\title{
A generic concept for Helium purification and liquefaction plant
}

\author{
Said Al Rabadi ${ }^{1 *}$, Martin Gwinner ${ }^{2}$ \\ ${ }^{I}$ Al-Balqa Applied University Faculty of Al-Hussen, Department of Chemical Engineering, \\ ${ }^{2}$ Technical Manager, The Linde Group, Dr.-Carl-von-Linde-Strasse 6-14, 82049 Pullach/ Germany
}

\begin{abstract}
This study describes and evaluates the performance of producing a pure Helium fraction from Helium extraction facility designed for cryogenic natural gas plants. A generic concept for obtaining a Helium pure fraction, which has relatively lower capital and operating costs should be provided. In order to achieve this objective, a new concept for obtaining a Helium pure fraction from a crude Helium fraction, is proposed based on simulations run under diverse process conditions regarding crude Helium gas' temperature, pressure and composition. This concept is characterized by; reducing the plant safety requirements due to the extensive separation of combustible components, and compact layout of Helium extraction plant. Further re-purification is included in the subsequent Helium liquefaction step through selective adsorption, hence then increasing the purity of the Helium product and reducing the plant energy consumption required for liquefying Helium-rich fraction and the valuable Helium boil-off routed from the storage facility. The Nitrogen-rich fraction is routed to Nitrogen liquefaction installation. Liquid Nitrogen is generated within Helium recovery facility for liquid Helium shielding and container cooling. Surplus gaseous Nitrogen either can be liquefied and used within cryogenic natural gas plant as process coolant or be vented to atmosphere.
\end{abstract}

Keywords: He liquefaction, cryogenic, plant topology, purification, energy consumption

\section{Introduction}

Helium is obtained commercially, almost exclusively, from a mixture of easily volatile natural gas components, which typically includes besides Helium, Methane, Nitrogen and traces of Hydrogen, Argon and other noble gases (Bowdon (1997) and Devold (2013)), the significant Helium concentration in the natural gas is promising enough to promote the installation of Helium production facility from cryogenic NG plants. In turn, Helium exists in the ambient air. However, the production of Helium from the ambient air is theoretically possible but is uneconomical, because of its low concentration. Helium is a colorless, odorless, non-toxic, noncorrosive and non-combustible gas. It has the lowest boiling point of gases in its liquid state of $4 \mathrm{~K}\left(-269^{\circ} \mathrm{C}\right)$ at atmospheric pressure (Singh et al.(2017)). Helium today has numerous applications, in view of the rapidly increasing demand for Helium, ranging from its use in parade balloons to space technology (Cosmos et al.(2011)), food industry as conservative material and cryogenics. The market price of metric ton of liquid Helium is about five times the value of liquefied natural gas (LNG) (Devold (2013)). As a strategic commodity Helium production and distribution will gain increasing importance in the future, since more high-tech applications make use of its unique properties. Understanding the basics of its manufacturing steps will promote process designers and end consumers as well as those involved with supply and distribution in making better decisions. In the recent decays, several techniques were found for Helium separation from volatile natural gas (NG) components; such as selective permeation of Helium through nonporous plastic membranes from polystyrene or ethyl cellulose, presented in (Brubaker et al.(1954), Scholes et al.(2017)). Selective permeation of Helium has the only advantage, which would allow the extraction of Helium without the treatment of bulk NG fraction. However, the membranes were neither sufficiently selective toward Helium that affects the purity of the product to be of practical interest. Cahill et al.(2018) described a recovery method based on the permeation of Helium through fused Silica capillaries. Silica is very selective to Helium from NG and consequently a very pure product can be obtained in a single separation step. However, these capillaries have a limited design pressure, hence low permeation rate at ambient temperatures is obtained. For a large rate, elevated figures of operating pressure are required. New recently technique was designed to recover Helium for cold spray applications based on pressure swing adsorption (PSA) method (Legoux (2010)). Helium is recovered at elevated pressure figures and a relatively high purity. A considerable performance of this technique is obtained only for a relevant application in aerospace technology, however, applying this Helium recovery system for other industry applications makes it economically unviable, since restrictions on the plant capacity and product purity figures are found. For a significant percentage of Helium in NG, it is worthy to extract Helium form crude Helium fraction obtained from cryogenic NG facilities. Figure 1 shows a typical cryogenic NG plant, where the process stages include Feed gas compression in order to bring the feed NG to the operating feed pressure. Next NG purification, where heavy hydrocarbons (HHC), COx, NOx as well sulphur components are extracted from NG.After this stage NG is wet and is needed to get a water free stream in the dehydration unit. In the cold part of the plant, NG is brought to liquid phase in the liquefaction unit, where LNG is produced and finally routed to Storage Unit. Nitrogen rejection unit (NRU) is required to separate $\mathrm{N}_{2}$ from NG stream in order to meet heating value of bulk NG. Nitrogen due to its lower boiling temperature than that of Methane basically concentrates in two NRU effluents that service as crude Helium fractions; Low Pressure (LP) Warm and High Pressure (HP) Cold gas streams. These process streams concentrate relatively high Helium fractions. The main difference between these two streams is the process temperature, pressure and composition. HP Cold stream gas is obtained from the warm part of NRU process, which is at the ambient temperature and under relatively low pressure.

Received on February $16^{\text {th }}, 2019$; accepted on $25^{\text {th }}$ April, 2019 Correspondence concerning this article should be addressed to Said Al Rabadi (e-mail address said.alrabadi@bau.edu.jo). ORCID of Said Al Rabadi: https://orcid.org/0000-0002-6007-2853. 
Whereas LP Cold gas is routed from the cold part of the NRU process that has a temperature of liquefied NG, around $100 \mathrm{~K}$ ($160^{\circ} \mathrm{C}$ ), and relatively higher figures than the atmospheric pressure (Al Rabadi et al.(2018), Smith (1996) and Kumar et al.(2014)).

The major capital expenses (CAPEX) is the Helium liquefaction unit, where it determines the economic size of Helium recovery plant due to energy consumption and product purity. This inelastic cost consists mainly of Helium liquefaction and recycle compression. Some large Helium production plants, taken onstream, are summarized in Table 1, where their production rate lies in the range of 1,300-2,000 Tpa. As can be deduced from Table 1, mainly Helium production plants were built utilizing Crude Helium fraction obtained from cryogenic NG facilities. In 1980's \& 1990’s

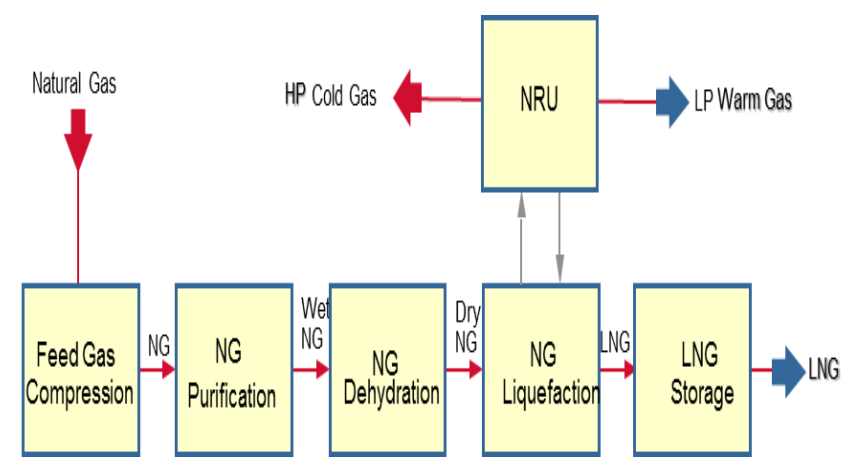

Fig. 1 Block diagram of a typical cryogenic NG plant

Helium demand grew accompanied with demand for large LNG production plants as well the need for NRU plants. In earlier Helium production plants, Helium was the key product, whilst in the preceding facilities Helium was a byproduct of large cryogenic NG facilities (LNGs, NRUs), which mostly implement TSA concept. An increasing demand was becoming supplied by privately held crude Helium firms contracted by industrial NG companies, leading to installation of Helium purification and liquefaction plants located near to existing NG industrial facilities. The purity of Helium product is found to be in the range of $90-96 \%$ (Devold (2013), Smith et al.(1997), Kumar et al.(2013) and Singh (2017)). Pure Helium is obtained by cooling it to cryogenic temperature and thereby condensing large portion of the Nitrogen in $\mathrm{N}_{2}$ Removal Unit.

\section{Materials and Methods}

In this study, the two process streams, obtained from cryogenic NG facility for Helium production plant, are considered for further design investigations. In turn, crude Helium gas content exceeds the figure of 10 mol-\% of the relevant stream composition, Table 2. These figures for crude Helium composition are deduced from on-stream Helium production facilities, (Devold (2013), Smith et al.(1997), Kumar et al.(2013), Singh (2017) and (Bowdon (1997)). The main objective is to get a new concept that must be adaptive for diverse crude Helium stream conditions; HP Cold and LP Warm streams. If pressure of crude Helium gas is below 2 bar, an upstream Feed Gas Compression Unit is required. In this study, theoretical investigations on Helium distillation, purification and liquefaction process with different plant topologies were performed, utilizing the so called UNISIM as the process simulator. The purpose of these theoretical investigations is to identify the improvements of process topology for a new concept for Helium extraction and production plant, that is valid over a pre-determined range of operating conditions, including crude Helium temperature, pressure and composition. The comparison criteria include the consumption of specific compressor shaft power as well utilities (LIN, GAN and tempered cooling water (TCW)), Helium recovery percentage and potential product purity. The LHe product specifications are onsidered, in turn, as optimization constraints, Table 3. Ambient air, needed for $\mathrm{H}_{2}$ Removal Unit that services as a source for $\mathrm{O}_{2}$, is responsible for the extraordinary product composition for Argon, Neon and $\mathrm{O}_{2}$ in the product stream. As listed, the objective LHe

Table 1 List of large extraction Helium plants worldwide (Devold (2013), Smith et al.(1997), Kumar et al.(2013) and Singh (2017)

\begin{tabular}{|c|c|c|c|c|}
\hline Plant & Owner & Location & $\begin{array}{l}\text { Start } \\
\text { Up }\end{array}$ & Product \\
\hline NRU & Exxon-mobile & $\begin{array}{l}\text { Shute Creek, } \\
\text { WY }\end{array}$ & 1966 & Pure He \\
\hline NRU & $\begin{array}{l}\text { Polish Oil \& Gas } \\
\text { Co. }\end{array}$ & $\begin{array}{l}\text { Odolanow, } \\
\text { Poland }\end{array}$ & 1977 & Pure He \\
\hline Helium & Nitrotec & $\begin{array}{l}\text { Cheyenne Wells, } \\
\text { CO }\end{array}$ & 1980 & Pure HE \\
\hline NRU & Pioneer & Satanta, KS & 1993 & $\begin{array}{l}\text { Crude } \\
\mathrm{He}\end{array}$ \\
\hline NRU & C.I.G. & Lakin, KS & 1995 & $\begin{array}{l}\text { Crude } \\
\mathrm{He}\end{array}$ \\
\hline LNG & Helios & Arzew, Algeria & 1995 & Pure He \\
\hline Helium & Keyes Helium & Keyes, OK & 1996 & Pure He \\
\hline NRU & Pioneer & Fain, TX & 1997 & $\begin{array}{l}\text { Crude } \\
\mathrm{He}\end{array}$ \\
\hline NRU & BP Amoco & Ulysses, KS & 1998 & $\begin{array}{l}\text { Crude } \\
\mathrm{He}\end{array}$ \\
\hline LNG & Philips Petroleum & Rock Hill, TX & 2001 & $\begin{array}{l}\text { Crude } \\
\mathrm{He}\end{array}$ \\
\hline LNG & Ras Gas & Qatar & 2005 & Pure He \\
\hline LNG & Helison & Skikda, Algeria & 2006 & Pure He \\
\hline LNG & Linde & $\begin{array}{l}\text { Darwin, } \\
\text { Australia }\end{array}$ & 2009 & Pure He \\
\hline NRU & Cimarex & Big Piney, WY & 2011 & Pure He \\
\hline
\end{tabular}

Table 2 Process parameters of HP Cold and LP Warm HeRUs

\begin{tabular}{lccc}
\hline Conditions & Unit & HP Cold & LP Warm \\
\hline Temperature & {$\left[{ }^{\circ} \mathrm{C}\right]$} & -160 & 30 \\
Pressure & {$[\mathrm{bar}]$} & 2.8 & 1.5 \\
Composition & & & \\
$\mathrm{Ar}$ & {$[\mathrm{mol}-\%]$} & 1.0 & 0.2 \\
$\mathrm{CH}_{4}$ & {$[\mathrm{~mol}-\%]$} & 1.0 & 1.0 \\
$\mathrm{H}_{2}$ & {$[\mathrm{~mol}-\%]$} & 3.0 & 1.1 \\
$\mathrm{He}$ & {$\left[\mathrm{mol}^{-} \%\right]$} & 31.3 & 10.8 \\
$\mathrm{~N}_{2}$ & {$\left[\mathrm{~mol}_{-} \%\right]$} & 63.7 & 86.9 \\
Specified flow rate & {$\left[\mathrm{Tpa}_{\mathrm{Crude} \mathrm{He}} / \mathrm{Tpa}\right.$} & \\
\hline
\end{tabular}


purity exceeds the He product purity obtained from on-stream reference plants, (Devold (2013), Smith et al.(1997), Kumar et al.(2013), Singh (2017) and (Bowdon (1997)). Practically, this significant He product purity could be achieved due to further re-

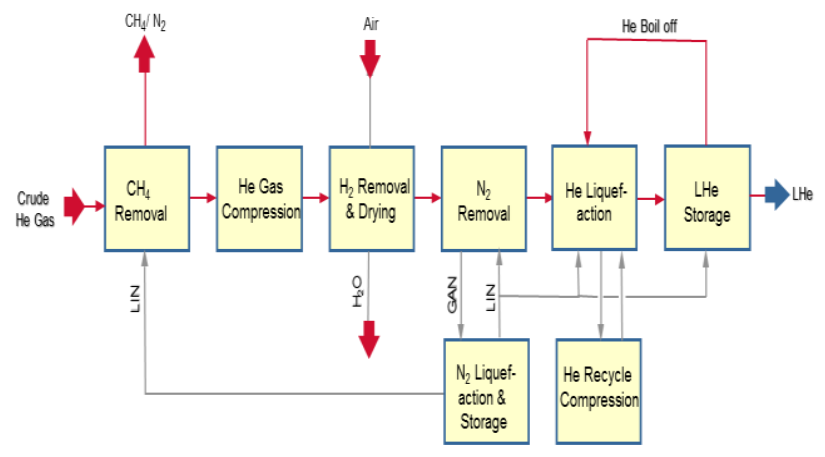

Fig. 2 Block diagram for LP Warm HeRu purification in the subsequent $\mathrm{He}$ Liquefaction Unit through selective adsorption of the remaining impurities like Hydrogen, Argon and other inert components, hence then increasing the purity of the Helium product and reducing the plant energy consumption, that is required for liquefying Helium-rich fraction and the valuable Helium boil-off routed from the LHe storage Unit.

\begin{tabular}{lcc} 
Table 3 LHe Product Specifications & \\
\hline $\mathrm{C} 1+$ & {$[\mathrm{ppm}]$} & 0.5 \\
$\mathrm{CO} 2+\mathrm{CO}$ & {$[\mathrm{ppm}]$} & 0.5 \\
Helium & {$[\mathrm{mol}-\%]$} & 99.995 \\
Hydrogen & {$[\mathrm{ppm}]$} & 1 \\
Oxygen & {$[\mathrm{ppm}]$} & 1 \\
Neon & {$[\mathrm{ppm}]$} & 2 \\
Nitrogen + Argon & {$[\mathrm{ppm}]$} & 5 \\
Water & {$[\mathrm{ppm}]$} & 1.5 \\
\hline
\end{tabular}

\section{Results and Discussion}

The employed worldwide processes to recover Helium in commercial quantities is based on partial condensation of NG components, or the so called traditional temperature swing adsorption (TSA) (Al Rabadi et al.(2012), Bölt et al.(2002), Stuber (1987) Weisend et al.(2007) and Berdais (2008)). The main essential steps are required for Helium production from cryogenic natural gas plants; distillation, purification and liquefaction, refer to Figure 2. In details, the LP Warm Crude Helium gas is routed to $\mathrm{CH}_{4}$ removal unit. Most of Methane is extracted in $\mathrm{CH}_{4} / \mathrm{N}_{2}$ column, liquefied Nitrogen (LIN) obtained from downstream $\mathrm{N}_{2}$ liquefaction and storage unit is implemented as reflux stream for the $\mathrm{CH}_{4} / \mathrm{N}_{2}$ column, the $\mathrm{N}_{2} / \mathrm{CH}_{4}$ fraction could be safely vented to the atmosphere in case of low Methane content or could be routed back to the mother cryogenic NG plant in case of a relatively significant Methane content. Then crude Helium gas is compressed and routed to $\mathrm{H}_{2}$ removal unit. There $\mathrm{H}_{2}$ is removed by an exothermic catalytic reaction with $\mathrm{O}_{2}$ obtained from ambient air, process $\mathrm{H}_{2} \mathrm{O}$ is produced and must be removed in the downstream drying unit. Then the Enriched Helium fraction is routed to $\mathrm{N}_{2}$ removal unit for further purification. This unit mainly consists of multiple flash drums at different pressure levels and two cryogenic plate and frame heat exchangers (PFHE). The produced $\mathrm{N}_{2}$ rich stream is routed to a parallel $\mathrm{N}_{2}$ liquefaction unit. The plant is self-dependent according to production/ consumption of LIN. There gaseous Nitrogen (GAN) is liquefied within Helium recovery unit ( $\mathrm{HeRu}$ ) to produce $\mathrm{LIN}$, which is used as reflux for $\mathrm{N}_{2} / \mathrm{CH}_{4}$ column, refrigerant of $\mathrm{N}_{2}$ removal unit, pre-coolant of He liquefaction unit and finally shielding of liquefied Helium (LHe) tank. He liquefaction Unit (TSA) consists of a series of PFHEs located inside a cold box, pre-cooling of pure Helium gas is provided by LIN. Helium Liquefaction and sub-cooling duties are provided by multi stage expander/boosters using Helium recycle as refrigerant (Wang et al.(2013)). Cold adsorption for traces of

Nitrogen, Hydrogen and inert gases provides further product purification (Das et al.(2012)). Finally, LHe is stored in a special storage tanks, where LIN is used as radiation shields to minimize LHe boil off due to heat ingress from ambient into inner Dewar. He Recycle compression unit is implemented to raise the pressure of LP \& Medium Pressure (MP) recycle Helium stream to HP figures. Helium Recycle compression is provided by multi stage oil lubricated screw type compression, in order to minimize Helium gas leakage. Currently, there are only two key firms offering large Helium liquefiers; Linde Kryotechnik and Air Liquide (Kumar et al.(2013)). The method, worldwide implemented, for production Helium is basically the traditional TSA method. This method consists of PFHE and adsorption drums (Singh et al.(2017) and Kumar et al.(2014)). Normally two adsorbers are used, one in adsorption and the other in regeneration mode. The adsorption mode includes the operation at a temperature of

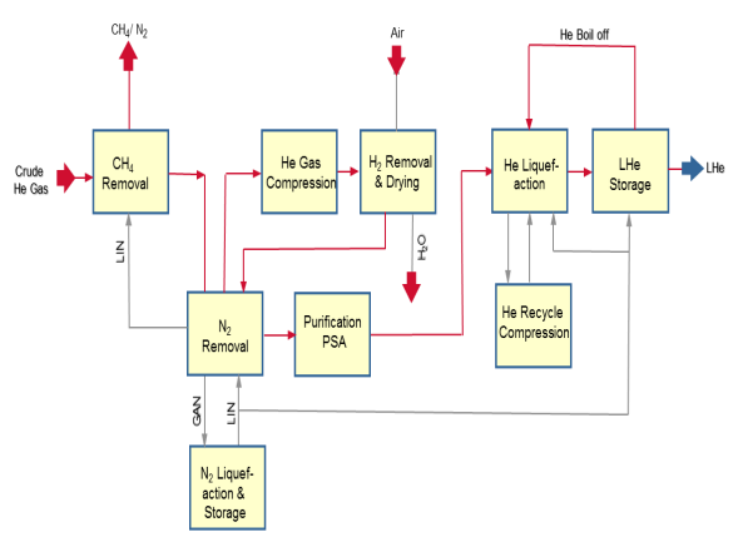

Fig. 3 Block diagram for HP Cold HeRu minimum $80 \mathrm{~K}\left(-193^{\circ} \mathrm{C}\right.$ ) (Bölt et al. (2002)). while the regeneration mode is a sophisticated recycle including evacuation, warm-up \& cool-down from 80 to $200 \mathrm{~K}\left(-193^{\circ} \mathrm{C}\right.$ to $\left.-73^{\circ} \mathrm{C}\right)$ within few hours. Here, several problems might occur in the control valve and piping systems, leading to Helium losses and hence decreasing recovery rates. Such production problems with Helium leakages and the sophisticated recycle routines are drastically reduced for HP Cold HeRu. Whilst an additional process modification is required in the 
plant topology since HP Cold HeRU is cold enough, and could serve to provide the pre-cooling duties in PFHE in $\mathrm{N}_{2}$ Removal Unit, this modification is illustrated in Figure 3. With respect to LP Warm HeRU process, the significant modification indicates that the crude Helium gas is warmed up in the PFHE in the downstream $\mathrm{N}_{2}$ Removal Unit, then it is routed to Helium Gas Compression Unit. This modification insures a relatively lower specific energy consumption due to utilizing the coldness in the crude He gas in precooling. After Helium Enriched Gas is purified in $\mathrm{H}_{2}$ removal and dried, then it is re-routed to $\mathrm{N}_{2}$ Removal Unit.

This stream is cooled down using LIN. Nitrogen traces from Enriched Helium Gas are removed, and Helium-rich stream is routed to He Liquefaction Unit. The performance of Helium production plant for both design cases is summarized in Table 4. The value for helium recovery percentage exceeds the value of $98 \%$, which is relatively higher than the findings in (Brubaker et al.(1954), Cahill et al.(1998), Legoux et al.(2010) and Scholes et al.(2017)), there a recovery percentage of about $85 \%$ was reported for the permeability methods. Mainly Helium losses occur in He Liquefaction Unit, hence a warm HP He fraction is used for regenerating the adsorption vessels, integrated in He Liquefaction Unit, from the adsorbed components on the molecular sieve. This regenerated gas is vented to the atmosphere. Regarding the specific energy consumption values, there is a relatively significant difference is obtained for both design HeRUs. This difference is explained for He production from LP Warm feed gas, the crude Helium pressure is below 2 bar, so that upstream feed gas compression is required. Another difference in specific energy consumption between both design cases is found in $\mathrm{N}_{2}$ Removal units, there higher compressor shaft power is required due to higher $\mathrm{N}_{2}$ content in LP Warm feed gas, in order to liquefy the resulting GAN stream. Surplus gaseous GAN fraction can be recycled to Nitrogen liquefaction installation, depending on LIN demand. LIN serves as utility stream to provide Helium precooling duty (two pre-cooling stages are foreseen) before liquefaction, furthermore as reflux for the $\mathrm{N}_{2} / \mathrm{CH}_{4}$ separation column through purging Methane content from crude Helium fraction and in radiation shields of liquid Helium storage tanks. This finding is consistent as well with the specific LIN and GAN consumption for He production from LP Warm with respect to that from HP Cold HeRUs. TCW quantities are calculated based on $10 \mathrm{~K}$ as maximum allowable temperature increase for TCW stream. Large amounts of TCW are required due to need for cooling the Enriched He stream downstream the $\mathrm{H}_{2}$ Removal unit. This is an exothermic catalytic reaction, and the outlet process temperature of this stream, according to process simulations, exceeds the figure of $300^{\circ} \mathrm{C}$. This temperature is subject to variation according to the variation of $\mathrm{H}_{2}$ content in crude $\mathrm{He}$ gas. More quantities of surplus GAN are obtained in case of LP Warm feed process. This amount of GAN, due to environmental and plant safety aspects, could be either vented to atmosphere, or could be liquefied and used for process cooling in the main cryogenic NG plant.

\subsection{Process Improvements}

Process modifications are suggested through the integration of PSA

Table 4 Performance criteria of Helium extraction and production plant

\begin{tabular}{lcc}
\hline Crude He Feed & $\begin{array}{c}\text { HP } \\
\text { Cold }\end{array}$ & $\begin{array}{c}\text { LP } \\
\text { Warm }\end{array}$ \\
\hline Helium Recovery Percentage [\%] & 98.7 & 98.6 \\
Expected Helium losses & & \\
$\mathrm{H}_{2}$ Removal \& Drying [\%] & & \\
$\mathrm{CH}_{4}$ Removal [\%] & 0.20 & 0.26 \\
$\mathrm{~N}_{2}$ Removal [\%] & 0.01 & 0.10 \\
$\mathrm{He}_{2}$ Liquefaction [\%] & Traces & Traces \\
LHe Storage [\%] & 1.0 & 1.0
\end{tabular}

Expected specific energy consumption

Feed Gas Compression [KW/Tpa $\left.\mathrm{LHe}_{\mathrm{Le}}\right]$

Helium Gas Compression [KW/Tpa $\left.{ }_{\mathrm{LHe}}\right]$

$\mathrm{N}_{2}$ Liquefaction [KW/Tpa $\left.\mathrm{LHe}_{\mathrm{Le}}\right]$

He Recycle Compression [KW/Tpa $\left.{ }_{\mathrm{LHe}}\right]$

Total $\left[\mathrm{KW} / \mathrm{Tpa}_{\mathrm{LHe}}\right]$

$\begin{array}{cc}- & 2.5 \\ 0.4 & 0.6 \\ 0.4 & 1.2 \\ 1.0 & 1.1 \\ 1.8 & 5.4\end{array}$

\section{Expected specific Utility Consumption}

$\begin{array}{lll}\text { LIN consumed [Tpa } & 5.2 & 9.4\end{array}$

$\begin{array}{lll}\text { GAN available }\left[\mathrm{Tpa}_{\mathrm{GAN}} / \mathrm{Tpa}_{\mathrm{LHe}}\right] & 6.0 & 12.8\end{array}$

$\begin{array}{lll}\text { GAN surplus }\left[\mathrm{Tpa}_{\mathrm{GAN}} / \mathrm{Tpa}_{\mathrm{LHe}}\right] & 0.8 & 3.8\end{array}$

TCW for machinery cooling [Tpa $\left.\mathrm{TCW}_{\mathrm{TCW}} / \mathrm{Tpa}_{\mathrm{LHe}}\right] \quad 320 \quad 454$

concept downstream the $\mathrm{N}_{2}$ Removal heat exchanger 25E01, upstream of He Liquefaction Unit for Nitrogen traces removal, Figure 4. Nitrogen Removal in Unit 25 is carried out in two stages; firstly, by a cryogenic step, the second step by adaption of PSA concept. The Helium-rich fraction after pr-cooling is routed to an adsorptive purification process (PSA), in which the high Helium pure fraction is obtained. PSA consists of several vessels, 25A01 A-E, constructed in parallel filled with a molecular sieve on a preassembled skid containing automatic valves, piping, and a surge tank, which promotes a shrinkage of plant footprint, as shown in Figure 5. PSA is easy to operate and is adaptable to the large Helium production plants. PSA removes all of the remaining impurities in the enriched Helium stream to less than 1.0 ppm (Al Rabadi et al.(2012), Berdais et al.(2008) and Das et al.(2012)). The feed stream is routed through one vessel where the impurities are adsorbed on the molecular sieve. After approximately few minutes in the range of 10 to 15 minutes, the feed is then routed through a fresh vessel and the initial empty vessel is de-pressurized allowing the molecular sieve to release the adsorbed components. Desorption is operated under low pressure and ambient temperature. However, during the venting of the PSA vessels, a significant amount of helium contained in this vented gas must still be recovered. Whereas, the traditional technique for Nitrogen removal is applying TSA concept, Figure 6. This concept is accomplished by compressing the gas and returning it to the inlet of 25E01 in N2 Removal unit. At this point the helium exiting the TSA is nearly pure except for trace amounts of Neon and possibly Hydrogen. The Neon and any Hydrogen are eventually removed by carbon adsorber, integrated in He Liquefaction Unit package at a temperature of $20 \mathrm{~K}\left(-253^{\circ} \mathrm{C}\right)$ resulting in inherently pure helium gas. Additional Vacuum Pump $25 \mathrm{C} 01$ required to reach deep cryogenic temperatures in 25D01. In details, TSA concept as illustrated in Figure 7, where two adsorbers 25D01 and 25D05 are 
implemented; one adsorber in adsorption whilst the other in regeneration mode. As can be conducted, a sophisticated regeneration cycle including evacuation, warm-up \& cool down from $80 \mathrm{~K}$ to $200 \mathrm{~K}\left(-193^{\circ} \mathrm{C}\right.$ to $\left.-70^{\circ} \mathrm{C}\right)$ according to simulations within hours.

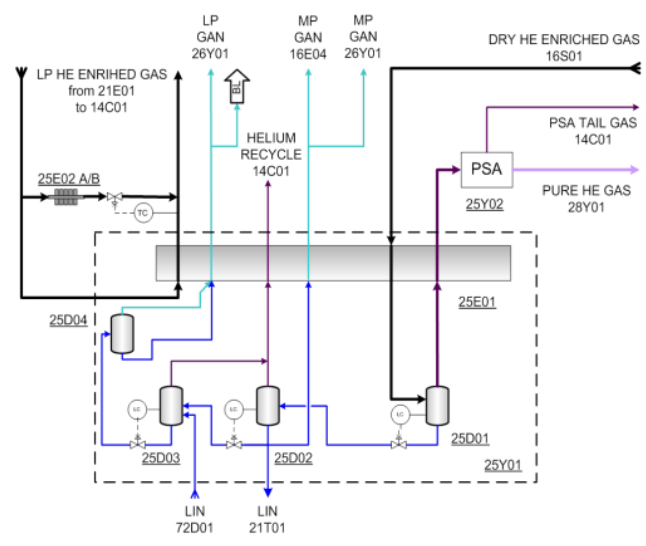

Fig. 4 Process Flow diagram (PFD) for Nitrogen Removal Unit implementing PSA concept

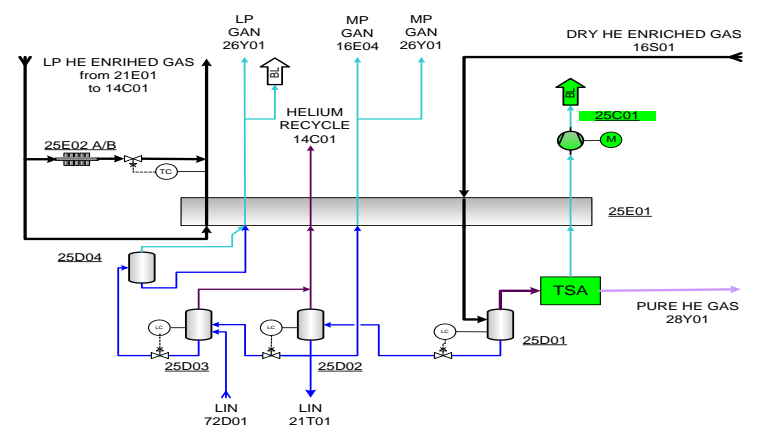

Fig. 6 PFD for Nitrogen rejection unit implementing TSA concept

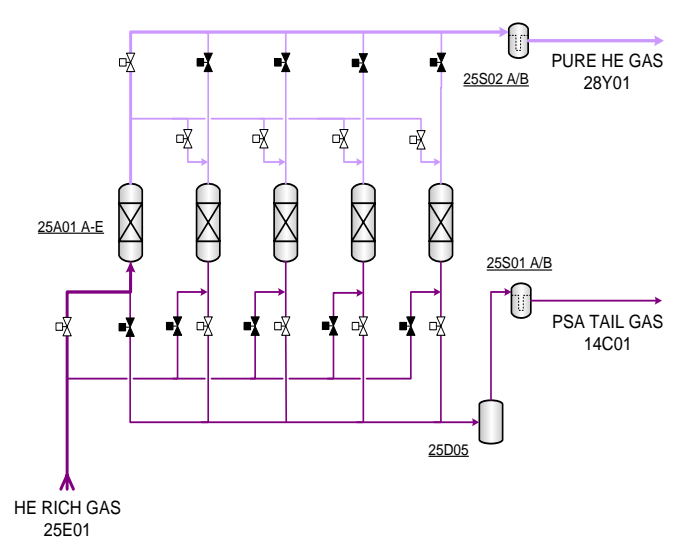

Fig. 5 PFD for PSA concept

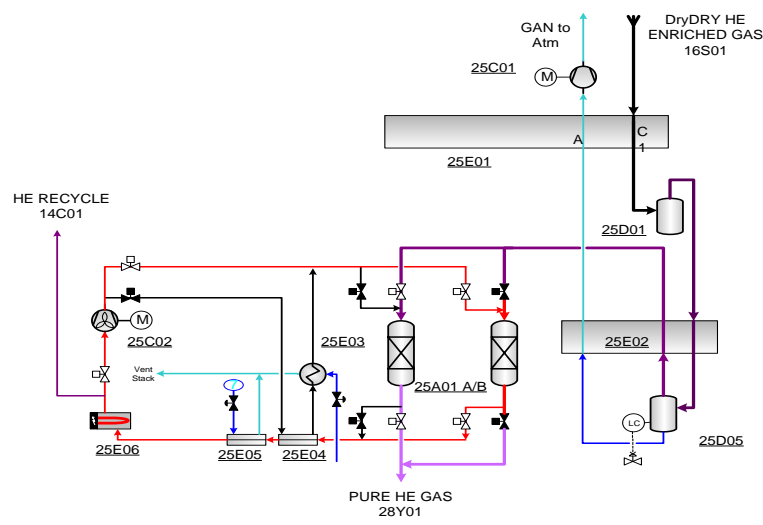

Fig. 7 PFD for TSA concept

In Table 5, comparison criteria between PSA and TSA are presented. Both concepts for purification of Enriched Helium stream, $\mathrm{N}_{2}$ Removal Unit is carried out in two stages; first one Nitrogen removal by cryogenic step, second stage: Nitrogen trace removal by either PSA or TSA adsorption. Meanwhile, $\mathrm{N}_{2}$ Removal with TSA is carried out in three stages; first and second ones are, identical to PSA concept, carried out under cryogenic conditions, third stage where an additional vacuum Pump is required to reach deep cryogenic temperatures, so called vacuum swing adsorption technique (VSA), through Table 5 HeRUs comparison between TSA and PSA concepts

\begin{tabular}{|c|c|c|}
\hline Concept & TSA/VSA & PSA \\
\hline $\begin{array}{l}\text { Expected Electrical Power Consumption } \\
\text { [\%] }\end{array}$ & 100 & 100 \\
\hline Expected Total Installation Costs [\%] & 100 & $\sim 50$ \\
\hline Plant Availability [ - ] & Fair & High \\
\hline Operating Conditions [ - ] & $\begin{array}{l}\text { Sophisticated } \\
\text { Cryogenic } \\
\text { Temperature }\end{array}$ & $\begin{array}{c}\text { Simple Ambient } \\
\text { Temperature }\end{array}$ \\
\hline
\end{tabular}
implementing a vacuum compressor 25C01. This represents a special form of TSA concept, with the only difference that adsorption \& desorption modes are done under low crude Helium pressure, hence no Feed gas compression is foreseen. LHe purity is obtained similar as PSA unit, so that VSA unit has no benefits compared to PSA. Moreover, VSA concept utilizes an additional rotating equipment, which has significant impact on plant availability. 


\subsection{Sensitivity Analysis}

Since the compositions of design feed streams deduce from design data for reference cryogenic NG plants, process simulations were conducted under crude Helium composition with a variation of a pre-determined component, in order to investigate the process performance. Helium production from HP Cold feed as the design case is considered. The pre-determined range of variation for the relevant component is based on variation in crude Helium gas' composition adapted from on-stream diverse gas composition for Helium production plant listed in Table 1. Methane content variation is altered in the range from 250 to $500 \%$, where its content increase is compensated by decreasing the Nitrogen content in Crude Helium gas, as shown in Table 6. Methane is mostly condensed in 21E01 and drawn-off with the GAN routed to atmosphere, Figure 8. Here simulations show that Methane is mostly drawn-off in the $\mathrm{N}_{2} / \mathrm{CH}_{4}$ Column $21 \mathrm{~T} 01$ and captured in GAN/C 1 fraction to a battery limit. Here the distillation Column $21 \mathrm{~T} 01$ should have a sufficient overdesign for $\mathrm{CH}_{4}$ removal. The overdesign factor of the distillation Column is in the range of $15 \%$ up to $20 \%$ for the foreseen Methane content' variation. As higher $\mathrm{CH}_{4}$ content is expected in crude He gas, consequently a higher amount of LIN is foreseen. Whilst LIN serves as reflux for the $\mathrm{N}_{2} / \mathrm{CH}_{4}$ separation column through purging Methane content from crude Helium fraction. In addition, Helium content variation was considered in the range of 70 to $130 \%$ for these investigations, where its content increase is compensated by decreasing the Nitrogen content in Crude Helium gas, as shown in Table 7.

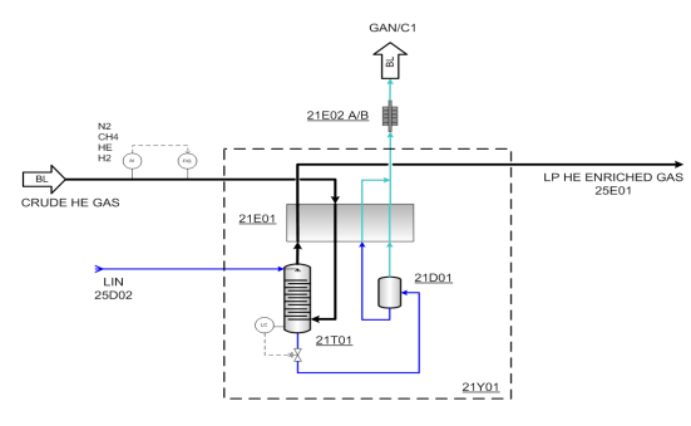

Fig. 8 PFD for cold box including $\mathrm{CH}_{4}$ Removalunit with $\mathrm{N}_{2} / \mathrm{CH}_{4}$ Column

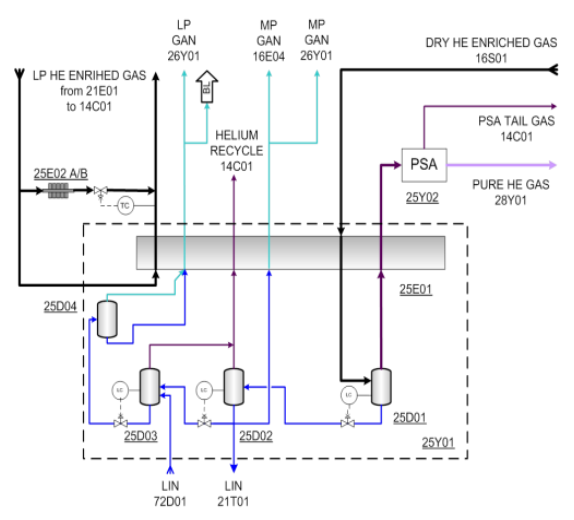

Fig. 9 PFD for cold box including $\mathrm{N}_{2}$ Removal Unit

Table 8 Sensitivity analysis with Argon content variation in the range of

\begin{tabular}{|c|c|c|c|c|}
\hline Case & Unit & HP Cold & $\begin{array}{l}\text { HP Cold } \\
200 \% \mathrm{Ar}\end{array}$ & $\begin{array}{l}\text { HP Cold } \\
300 \% \text { Ar }\end{array}$ \\
\hline \multicolumn{5}{|l|}{ Conditions } \\
\hline Temperature & {$\left[{ }^{\circ} \mathrm{C}\right]$} & -160 & -160 & -160 \\
\hline Pressure & [bar] & 2.8 & 2.8 & 2.8 \\
\hline \multicolumn{5}{|l|}{ Composition } \\
\hline Argon & [mol-\%] & 1.0 & 2.0 & 3.0 \\
\hline Helium & [mol-\%] & 31.3 & 31.3 & 31.3 \\
\hline Hydrogen & [mol-\%] & 3.0 & 3.0 & 3.0 \\
\hline Nitrogen & [mol-\%] & 63.7 & 62.7 & 61.7 \\
\hline Methane & [mol-\%] & 1.0 & 1.0 & 1.0 \\
\hline
\end{tabular}

Table 6 Sensitivity analysis with Methane content variation in the

\begin{tabular}{lcccc}
\multicolumn{5}{c}{ range of $100 \%$ to 500\% } \\
\hline Case & Unit & HP Cold & $\begin{array}{c}\text { HP Cold } \\
\mathbf{2 5 0 \%} \text { CH4 }\end{array}$ & $\begin{array}{c}\text { HP Cold } \\
\mathbf{5 0 0} \text { CH4 }\end{array}$ \\
\hline Conditions & & & & \\
Temperature & {$\left[{ }^{\circ} \mathrm{C}\right]$} & -160 & -160 & -160 \\
Pressure & {$[$ bara] } & 2.8 & 2.8 & 2.8 \\
Composition & & & & \\
Nitrogen & {$[$ mol-\%] } & 63.7 & 62.2 & 59.7 \\
Methane & {$[$ mol-\%] } & 1.0 & 2.5 & 5.0 \\
Helium & {$[\mathrm{mol}-\%]$} & 31.3 & 31.3 & 31.3 \\
Hydrogen & {$[\mathrm{mol}-\%]$} & 3.0 & 3.0 & 3.0 \\
Argon & {$[\mathrm{mol}-\%]$} & 1.0 & 1.0 & 1.0 \\
\hline
\end{tabular}

Table 7 Sensitivity analysis with Helium content variation in the range of $70 \%$ to

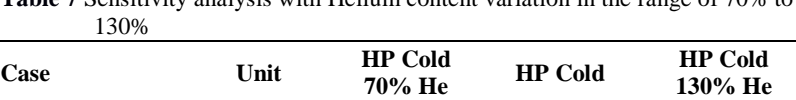

\begin{tabular}{lcccc} 
Case & Unit & $\begin{array}{c}\text { H0\% He } \\
\mathbf{7 0 n d i t i o n s ~}\end{array}$ & HP Cold & $\begin{array}{c}\text { HP Cold } \\
\mathbf{1 3 0 \%} \mathbf{H e}\end{array}$ \\
\hline $\begin{array}{l}\text { Temperature } \\
\text { Pressure }\end{array}$ & {$\left[{ }^{\circ} \mathrm{C}\right]$} & -160 & -160 & -160 \\
Composition & {$[\mathrm{bar}]$} & 2.8 & 2.8 & 2.8 \\
Argon & & & & \\
Helium & {$[\mathrm{mol}-\%]$} & 1.0 & 1.0 & 1.0 \\
Hydrogen & {$[\mathrm{mol}-\%]$} & $\mathbf{2 1 . 9 1}$ & 31.3 & $\mathbf{4 0 . 6 9}$ \\
Nitrogen & {$[\mathrm{mol}-\%]$} & 3.0 & 3.0 & 3.0 \\
Methane & {$[\mathrm{mol}-\%]$} & $\mathbf{7 3 . 0 9}$ & 63.7 & $\mathbf{5 4 . 3 1}$ \\
\hline
\end{tabular}

Table 9 Sensitivity analysis with Hydrogen content variation in the range of $200 \%$

\begin{tabular}{lcccc}
\multicolumn{2}{c}{ to $300 \%$} \\
Case & \multirow{2}{*}{ Unit } & HP Cold & HP Cold 200\% & HP Cold \\
& & & H2 & 300\% H2 \\
\hline
\end{tabular}

\section{Conditions}

Temperature

Pressure

Composition

Argon

Helium

Hydrogen

Nitrogen

Methane

$\begin{array}{cc}{\left[{ }^{\circ} \mathrm{C}\right]} & -160 \\ {[\mathrm{bar}]} & 2.8 \\ & \\ {[\mathrm{~mol}-\%]} & 1.0 \\ {[\mathrm{~mol}-\%]} & 31.3 \\ {[\mathrm{~mol}-\%]} & 3.0 \\ {[\mathrm{~mol}-\%]} & 63.7 \\ {[\mathrm{~mol}-\%]} & 1.0\end{array}$

$-160$

2.8

1.0

31.3

9.0

57.7

1.0 
Lower Helium content with a factor of $70 \%$ comparing to its design figure in HP Cold feed, as a result the process is comparable to turndown condition, so it is not regarded as critical. For the case of $130 \%$ Helium content with respect to its design figure in HP Cold feed, increased flow rates are expected through all units downstream $\mathrm{CH}_{4}$ Removal Unit. Hence then LIN demand is increased due to higher LHe production flow rate. As a major consequence a possible lack of Nitrogen is foreseen. Meanwhile, Argon content is varied in the range from 200 to $300 \%$, where its content increase is compensated by decreasing the Nitrogen content in Crude Helium gas, as shown in Table 8. According to Figure 9, Argon is condensed in 25E01 and is drawn-off with the liquid leaving 25D01. As a consequent, Argon is mostly condensed in $\mathrm{N}_{2}$ Removal Unit and accumulates within MP GAN stream, which is routed and liquefied in the downstream $\mathrm{N}_{2}$ liquefaction \& Storage unit, it could have a minor impact on LIN specifications. In total, Argon is an inert component in LIN and is not regarded as critical. Hydrogen content variation was considered in the range 200 to $300 \%$ for these investigations, where its content increase is compensated by decreasing the Nitrogen content in

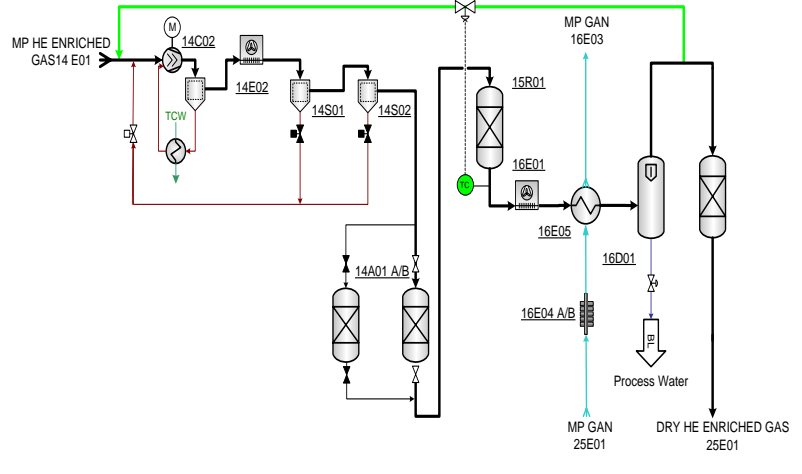

Fig. 10 PFD for $\mathrm{H}_{2}$ Removal \& Drying unit Crude Helium gas, as shown in Table 9. As a consequence, a significant raise in the outlet temperature of $\mathrm{H}_{2}$ reactor is expected due to the exothermic reaction for increasing Hydrogen content. Taking in consideration that the catalyst design temperature is around $500^{\circ}$ C, a temperature controller has to be implemented on the outlet stream of 15R01, Figure 10, along with associated recycle to Helium gas compressor 14C02. Therefore, a larger equipment sizing is foreseen due to recycle. For the investigated variation in the Hydrogen content, an overdesign factor in 15R01 of $25 \%$ should be given.

\section{Conclusions}

A generic concept for producing a Helium pure fraction with lower CAPEX is provided, which will be applicable over a spread range of feed gas pressure, temperature and crude Helium gas composition. This concept is characterized by: prior separation of the Methane fraction, which contributes in reducing the plant safety requirements (e.g. explosion protection) due to the extensive separation of combustible components. Compact plant footprint of Helium-rich fraction is achieved, and hence shrinkage in plant layout also eliminating Helium losses to atmosphere. Further re-purification is included in the subsequent He Liquefaction Unit through selective adsorption of the remaining impurities like Hydrogen, Argon and other inert components, hence then increasing the purity of the Helium product and reducing the plant energy consumption.

\section{Acknowledgments}

Special thanks for the support awarded by The Linde Group Firm in the conduction of this research work. This work substantially overlaps research interests between industry and the academia.

\section{Nomenclature}

$\begin{array}{ll}\text { Acronym } & \text { Description } \\ \text { CAPEX } & \text { Capital expenses } \\ \text { GAN } & \text { Gaseous Nitrogen } \\ \text { LHe } & \text { Liquefied Helium } \\ \text { LIN } & \text { Liquefied Nitrogen } \\ \text { HeRU } & \text { Helium recovery unit } \\ \text { HP } & \text { High pressure } \\ \text { LNG } & \text { Liquefied natural gas } \\ \text { LP } & \text { Low pressure } \\ \text { MP } & \text { Medium pressure } \\ \text { NG } & \text { Natural gas } \\ \text { NRU } & \text { Nitrogen rejection unit } \\ \text { HEX } & \text { Heat exchanger } \\ \text { HHC } & \text { Heavy hydrocarbons } \\ \text { PFD } & \text { Process flow diagram } \\ \text { PFHE } & \text { Plate and frame heat exchanger }\end{array}$




$\begin{array}{ll}\text { PSA } & \text { Pressure Swing Adsorption } \\ \text { TCW } & \text { Tempered cooling water } \\ \text { Tpa } & \text { Ton per annum } \\ \text { TSA } & \text { Temperature Swing Adsorption } \\ \text { VSA } & \text { Vacuum swing adsorption }\end{array}$

\section{References}

Al Rabadi, S., R. Sapper, S. Emeish, and F. F. Banihani, "Improved configurations for liquefied natural gas recycles", Jord. Jour. of Eng. and Chem. Indus., 1, 19-37, (2018).

Al Rabadi S., M. Gwinner, A. Bub, and H. Bauer, German Patent and Trademark Office DE 102012000147A1, January (2012).

Berdais K. H., H. Wilhelm and T. Ungricht, "Improvements of Helium Liquefaction/refrigeration Plants and Applications", AIP Conference Proceedings, 985, 825-829 (2008).

Bölt M. and M. Gwinner, German Patent and Trademark Office DE10106484A1, August, (2002).

Bowden M. E., Chemical achievers: the human face of the chemical sciences, Chemical Heritage Foundation: Philadelphia, (1997).

Brubaker D. W., and K. Kammermeyer, "Separation of Gases by Plastic Membranes-Permeation Rates and Extent of Separation", Ind. Eng. Chem., 46, 733-739, (1954).

Cahill J. E. and D. H. Tracy, "Effects of Permeation of Helium through the Walls of Fused Silica Capillary GC Columns", Jour. of Sep. Sci., 21, 531-539, (1998).

Cosmos T. C., and M. Parizh, "Advances in whole-body MRI magnets", IEEE Trans Applied Super conductivity, 21, 2014-2019, (2011)

Das N. K., P. Kumar, C. Mallik, and R. K. Bhandari, "Development of a helium purification system using pressure swing adsorption", Current Science, 103, 631-634, (2012).

Devold, H., Oil and gas production handbook, An introduction to oil and gas production, transport, refining and petrochemical industry, $3^{\text {rd }}$ Edition, Oslo, (2013)

Kumar D., R. and S. Mishra, "Thermodynamic Analysis of Linde System for Liquefaction of Gases", Int. Jour. of Adv. Res. and Innov., 3, 172-178, (2013).

Kumar D. and R. S. Mishra, "Thermodynamic Comparison of Linde and Claude Systems for Liquefaction of Gases", Int. Jour. of Adv. Res. and Innov., 2, 40-49, (2014).

Legoux J. G., E. Irissou, S. Desaulniers, J. Bobyn, B. Harvey, W. Wong, E. Gagnon, and S. Yue, "Characterization and performance evaluation of a helium recovery system designed for cold spraying", Intrnational Thermal Spray Conference and Exposition, Thermal Spray: Global Solutions for Future Application (DVS-ASM), 560-565, May, (2010).

Scholes C. A., U. K. Gosh, and M. T. Ho, "The Economics of Helium Separation and Purification by Gas Separation Membranes", Ind. Eng. Chem. Res., 56, 5014-5020, (2017).

Singh G., J. Singh, J. Singh, and A. Singh, “Cryogenics (Helium Liquefaction)”, Int. Res. Jour. of Eng. and Tech., 4, 867-873, (2017).

Smith, J. M., M. Van Ness, and M. Abbott, Introduction to Chemical Engineering Thermodynamics, $5^{\text {th }}$ Edition, Mc-GRAW Hill International Editions, (1996).

Stuber W. G., D. W. Stuber and A. R. Winters, US Patent 4659351, April, (1987).

Wang B. M., Z. J. Hu, P. Zhang and Q. Li, "Development of a test rig for a helium twin-screw compressor", Advances in Cryogenic Engineering, Transactions of the Cryogenic Engineering Conference, Anchorage (Alaska), 1573, 1672-1678, (2013).

Weisend J. G., J. Barclay, S. Breon, J. Demko, M. DiPirro, J. P. Kelley, P. Kittel, A. Klebaner, A. Zeller, M. Zagarola, S. Van Sciver, A. Rowe, J. Pfotenhauer, T. Peterson, and J. Lock., Advances in Cryogenic Engineering, AIP Conference Proceedings, 985, 825-829, (2007). 